九州大学学術情報リポジトリ

Kyushu University Institutional Repository

\title{
A Progressive Data Warehouse of Institutional Research with Web API and Mashup Visualization
}

Masao, Mori

Toshie, Tanaka

Sachio, Hirokawa

http://hdl. handle. net/2324/25654

出版情報 : Proceedings of The Third International Conference on Computer Supported Education, pp.174-，2011-05

バージョン :

権利関係 : 


\title{
A PROGRESSIVE DATA WAREHOUSE OF INSTITUTIONAL RESEARCH WITH WEB API AND MASHUP VISUALIZATION
}

\author{
Masao Mori, Toshie Tanaka \\ Institutional Reserach Office, Kyushu University, Fukuoka, Japan \\ mori@ir.kyushu-u.ac.jp,tanaka@ir.kyushu-u.ac.jp \\ Sachio Hirokawa \\ Research Institute for Information Technology, Kyushu University, Fukuoka, Japan \\ hirokawa@cc.kyushu-u.ac.jp
}

Keywords: university evaluation, accreditation, institutional research, data warehouse, mashup

\begin{abstract}
We propose a progressive data warehouse which provides functions of operating statistics and their visualization for institutional research. The proposed data warehouse has a mashup programming environment with GUI and the users can share their programs. By sharing programs of data analysis, persons in charge of self-assessment seize an opportunity not only to create reports efficiently, but also to be able to improve their activities.
\end{abstract}

\section{INTRODUCTION}

For the last decade, it has become very important to establish PDCA cycles (an iterative process in business improvement, acronym of 'Plan-Do-CheckAction') in private enterprises as well as universities and research institutions. There are a number of reasons why this action has occurred, but the needs to implement quality assurance systems and to fulfill government grant requirements have provided the rationale for the improvement cycle of universities and research institutions. Quality assurance is realization of the 'Check' and the 'Action' processes of PDCA cycle. The 'Check' phase is mostly conducted as selfassessment.

In the 'Check' phase of PDCA cycle, we create self-assessment reports and collect their evidence. Evidence consists of text data (committee materials and documents, namely qualitative) and numerical data (statistics of students and faculties, namely quantitative).

All Japaneses universities are obliged to be evaluated by certified organization, called Institutional Certified Evaluation and Accreditation (ICEA, for short). In addition, all Japaneses national universities must be evaluated for the purpose of information disclosure to government and nation, called $\mathrm{Na}$ tional University Corporation Evaluation (NUCE, for short). They are called university evaluations which is undergone every six years. Universities must prepare self-assessment reports and their evidence. Figure 1 shows examples of classification for evidence which are necessary in the university evaluations. Figure 2 is total number of graphs and tables which we actually offered in the university evaluations.

\begin{tabular}{|c|l|l|}
\hline & Text Data & Numerical Data \\
\hline Individuals & $\begin{array}{l}\text { awards } \\
\text { features }\end{array}$ & $\begin{array}{l}\text { papers, } \\
\text { grants }\end{array}$ \\
\hline \multirow{2}{*}{ Organizations } & $\begin{array}{l}\text { materials, } \\
\text { regulation, } \\
\text { publication }\end{array}$ & $\begin{array}{l}\text { statistics of } \\
\text { education } \\
\text { and students }\end{array}$ \\
\hline
\end{tabular}

Figure 1: Examples classification of institutional information used in the university evaluations which were conducted in Kyushu University

\begin{tabular}{|l|r|r|}
\hline & text data & numerical data \\
\hline \hline ICEA & 145 & 50 \\
\hline Education(NUCE) & 58 & 47 \\
Research(NUCE) & 12 & 12 \\
\hline total & 215 & 109 \\
\hline
\end{tabular}

Figure 2: Number of items and statistics in university evaluations which were conducted in Kyushu University

How to store and manage text data efficiently is important, but in this paper we focus on management of numerical data. In Kyushu University, as there 
are 16 research faculties, 17 graduate schools, 11 undergraduate schools and 7 research institutions with the hospital, numbers of statistics of numerical data amounts to over 1500. Since the authors has been working on supporting the self-assessment reports of Kyushu University, we recognize that the problem of large numbers of statistics is crucial. Those statistics in the context of university evaluations are acquired by sorting and cross-tabulating tables of numerical data. Persons in charge of assessment in each school have to study such skills as cross-tabulating and SQL language. Though these persons are not full-time assessment staff, they must learn those skills in addtion to jobs of self-assessment.

The purpose of self-assessment is not creating reports, but reflecting activities of the university. To do so, it is useful to visualize statistics of numerical data in time series. Fundamental visualizations of numerical data are line or bar graphs, their combination, pie chart, radar chart and so on. It is difficult to choose generally which type of visualization is suitable for each statistic.

In order to manage statistics and their visualization, we propose a data warehouse with sharing skills on statistics and visualization using mashup technology. Data warehouse has become popular in institutional research. In our approach, mashup technology is introduced in data warehouse. By facility of mashup technology, persons in charge of selfassessment can become familiar with statistics and analyse from data warehouse.

The rest of paper consists as follows. In section 2 , we will introduce related work and argue an issue of data warehouse that enterprise data warehouse is not suitable for institutional research. In section 3, we propose a system sharing programs for statistics and their visualization. In section 4 , we conclude our approach.

\section{RELATED WORK}

Enterprise data warehouse has two styles, Inmon's style (Inmon, 1999) and Kimball's style (Kimball and Ross, 2002). While Inmon's style is a collection of data tables in 3rd normal form, called data warehouse and user interface of analysing tools, called data mart, data warehouse of Kimball's style forms a dimensional data model from which data mart extracts necessary data.

Considering problems mentioned in the introduction, common issue of both style data warehouse is that users are not supposed to develop analysing tools and visualizing skills. Staff in institutional research should be analysts as well as they are respected to develop data analysing programs. A feature of our approach is that every user can contribute to development of data warehouse tools without expertise on programming.

Interaction between users and data warehouse would be useful. Ferrández and Peral (2010) proposed such interaction that data warehouse offers question to users. Our approach focus on interaction between users in order to share their tools and skills.

Mashup is a new concept to combined web services and web databases with existing technologies such as XML and HTTP communications. Swashup DSL(Maximilien et al., 2007) and WMSL(Sabbouh et al., 2007) are domain specific language (DSL) for mashup, which do not assume programming skills like JavaScript, CGI and so on. Integrated user interfaces of mashup are proposed, for instance, Yahoo! Pipes, Mashup Feeds (Tatemura et al., 2007) and Damia (Altinel et al., 2007).

From viewpoint of simple and easy mashup programming and visualizing mashup data, we proposed and implemented a mashup programming environment (Mori et al., 2006) with GUI (Mori et al., 2007) which combines web databases. In our study Web databases are supposed to have Web API which offers structured data with HTTP requests. The system has four features. Firstly, every source of structured data, including search engines and local CSV files ${ }^{1}$, is defined an abstract I/O machine in the system, we call them resource component. Secondly we generalize UNIX-like pipeline and filters on the system. In the architecture of our system, UNIX-like filter operations like sorting and creating histogram are implemented. Graph generation programs are also implemented as kinds of filter operation as well. Thirdly, the system provides a GUI programming environment which helps users to create mashup programs intuitively and easily. Finally the system is served as a multiuser content management system in which users share mashup programs.

\section{THE PROPOSED SYSTEM}

Our proposing system consists of three parts. Overview is shown in figure 6.

The first part is a data warehouse for institutional research with Web API. The mashup programming environment can include the data warehouse as a resource component. The second part is a GUI mashup programming environment for visualization and its

\footnotetext{
${ }^{1}$ User can upload CSV files as resource components
} 
execution environment. The GUI mashup programming environment serves fundamental data operations, for instance, sorting and counting words. Moreover Fundamental visualizations can implemented in the environment. The third part is a contents management system to share mashup programs of visualization with other users. By sharing programs, user can copy and revise those programs more easily than create programs from scratch.

Figure 3 shows a mashup program example, named CSEDU2011-5.Cgi, which processes a article databases (Web database of articles published by Information Processing Society of Japan, IPSJ for short) with a histogram filter (counting authors' name) and one graphic (pie chart). A green rectangle is a resource component (an article database of IPSJ) in which red dots on upper side and down side represent input (search words) and output (search result) respectively. While the left blue rectangle at the bottom is a browser, the right blue rectangle is a histogram filter which counts appearance of authors from search result. The yellow rectangle shows a pie chart visualizing results of the histogram filter. Arrows between rectangles represent correspondence of attributes of structured data. Figure 4 shows an execution of CSEDU2011-5. cgi ${ }^{2}$. Given search word 'web', the program returns search result of IPSJ with a pie chart which represents proportion of numbers of authors in the search result. Figure 5 is the content management system of the mashup programming environment in which users share mashup programs. Implementation is progressing and will be completed in April 2011.

\section{CONCLUSION}

The proposed system has two contribution. Firstly, simple and easy programming environment with GUI increase programming users. This means that web application programmers as well as data analysts create mashup programs. Secondly, by sharing programs in the proposed system, one can curbs the development cost of application programs for data analysis. One of the problems of data analysis in institutional information is diversity rather than quantity. Users can create a new analysing program by reusing and composing shared programs. The proposed mashup programming methods enables us to combine internal institutional information as well as external information.
In this paper we propose a progressive data warehouse which cooperates with a GUI environment of mashup visualization. The next step of our approach is to classify shared programs of statistics and their visualization.

\section{REFERENCES}

Altinel, M., Brown, P., Cline, S., Kartha, R., Louie, E., Markl, V., Mau, L., Ng, Y.-H., Simmen, D., and Singh, A. (2007). Damia: a data mashup fabric for intranet applications. In Proceedings of th 33rd international conference on Very Large Databases, pages 1370-1373. VLDB Endowment.

Ferrández, A. and Peral, J. (2010). The benefits of the interaction between data warehouses and question answering. In Proceedings of the 2010 EDBT/ICDT Workshops, volume 426 of ACM International Conference Proceeding Series.

Inmon, W. (1999). Data Warehouse Performance. Wiley.

Kimball, R. and Ross, M. (2002). The Data Webhouse Toolkit : 2nd edition. Wiley.

Maximilien, E. M., Ranabahu, A., and Tai, S. (2007). Swashup: Situational web applications mashups. In 22nd International Conference on Object-Oriented Programming Systems, Languages, and Applications, OOPSLA 2007 - Companion, pages 797-798.

Mori, M., Nakatoh, T., and Hirokawa, S. (2006). Functional composition of web databases. In Proceedings of International Conference Asian Digital Libraries 2006, Lecture Note in Computer Science 4312, pages 439448. Springer Verlag.

Mori, M., Nakatoh, T., and Hirokawa, S. (2007). Links and cycles of web databases. In The 4th Italian Workshop on Semantic Web Applications and Perspectives, pages 21-30. Dip. di Informatica, Universitá degli Studi di Bari.

Sabbouh, M., Higginson, J., Semy, S., and Gagne, D. (2007). Web mashup scripting language. In Proceedings of the 16th international conference on World Wide Web 2007, pages 1305 - 1306. ACM Press.

Tatemura, J., Sawires, A., Po, O., Chen, S., Candan, K. S., Agrawal, D., and Goveas, M. (2007). Mashup feeds: Continuous queries over web services. In Proceedings of the 2007 ACM SIGMOD international conference on Management of data, pages 1128 - 1130. ACM Press.

\footnotetext{
${ }^{2}$ This program can be executed if one access the URL http://www.ir. kyushu-u.ac.jp/ masa/Development/PSM/Generated/CSEDU2011_5.cgi.
} 


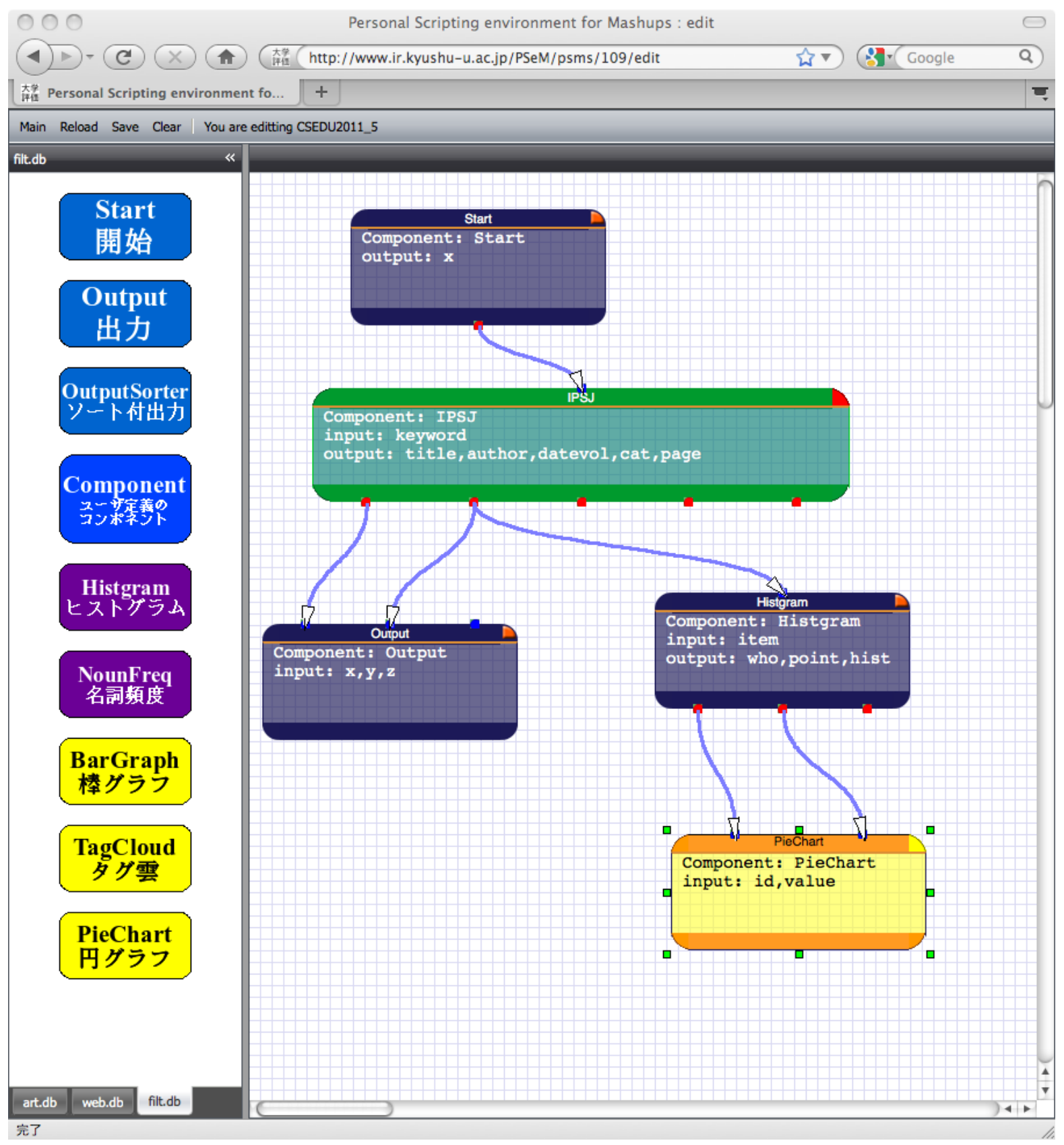

Figure 3: GUI editor of mashup 


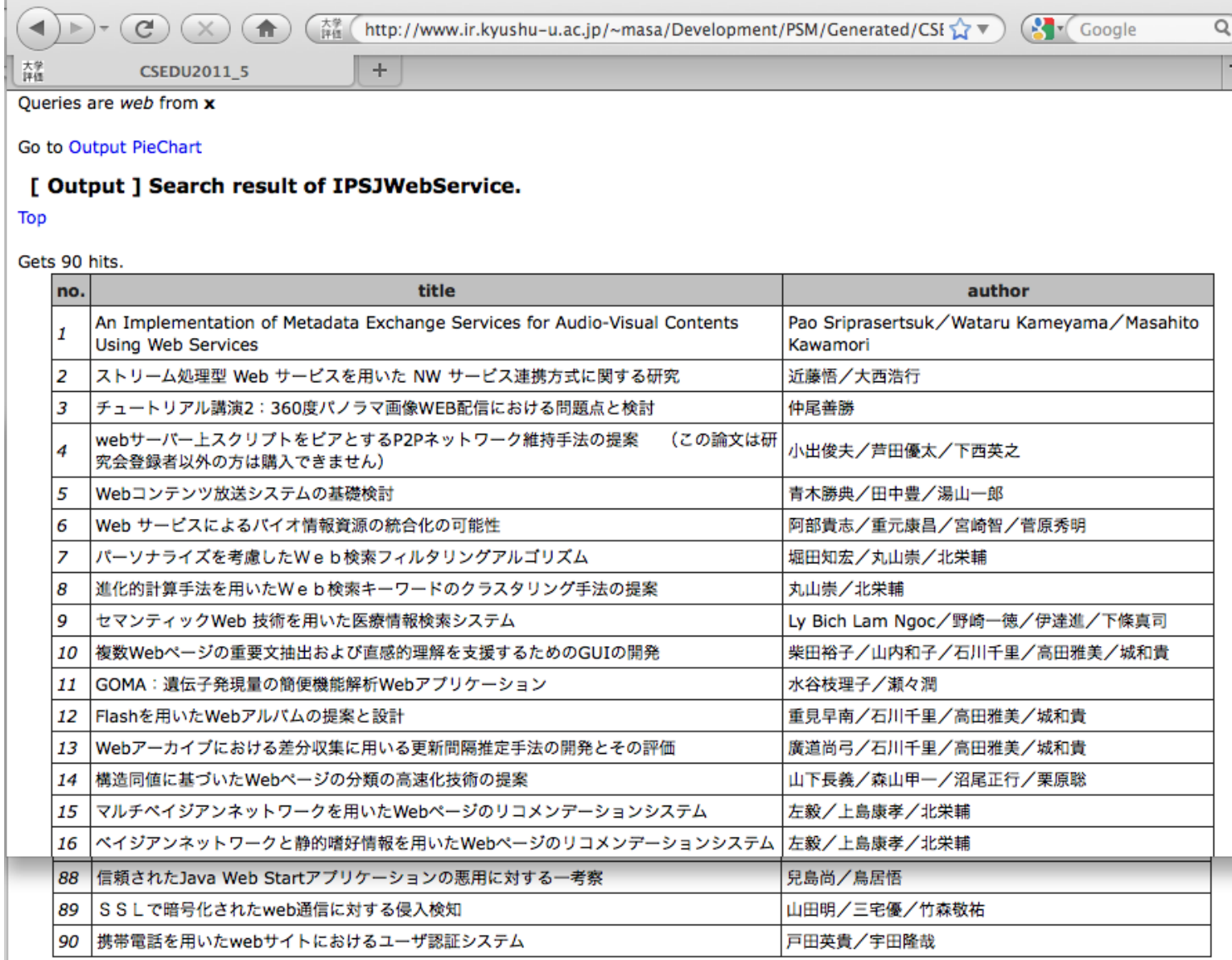

Gets 229 hits.

\section{[ PieChart ]}

Top

Upper 100 items

chart by amCharts.com

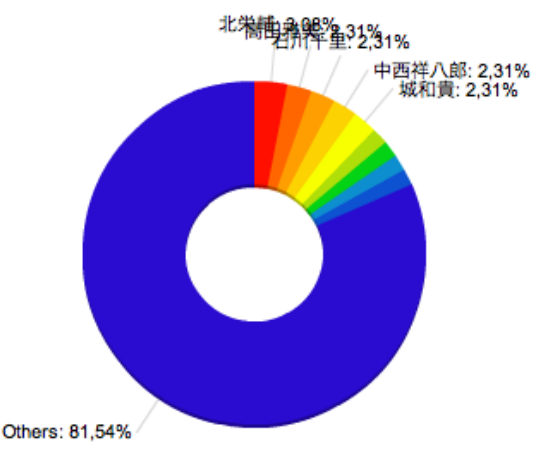
北栄輔
高田漼美
石川千里
中西祥八郎
城和貴
西田友是
上島康孝
長慎也
香川考司
Others 


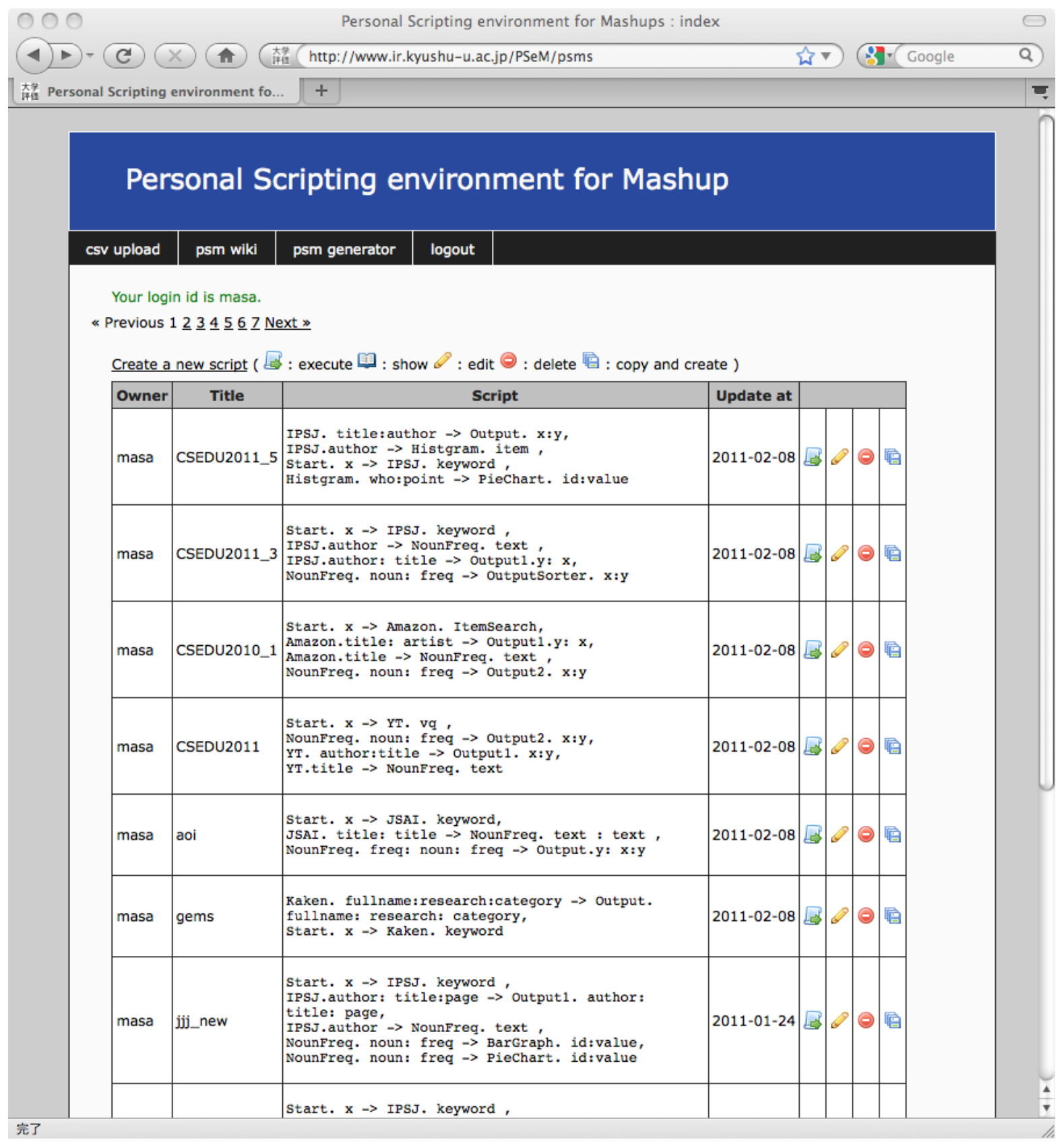

Figure 5: Sharing mashup 


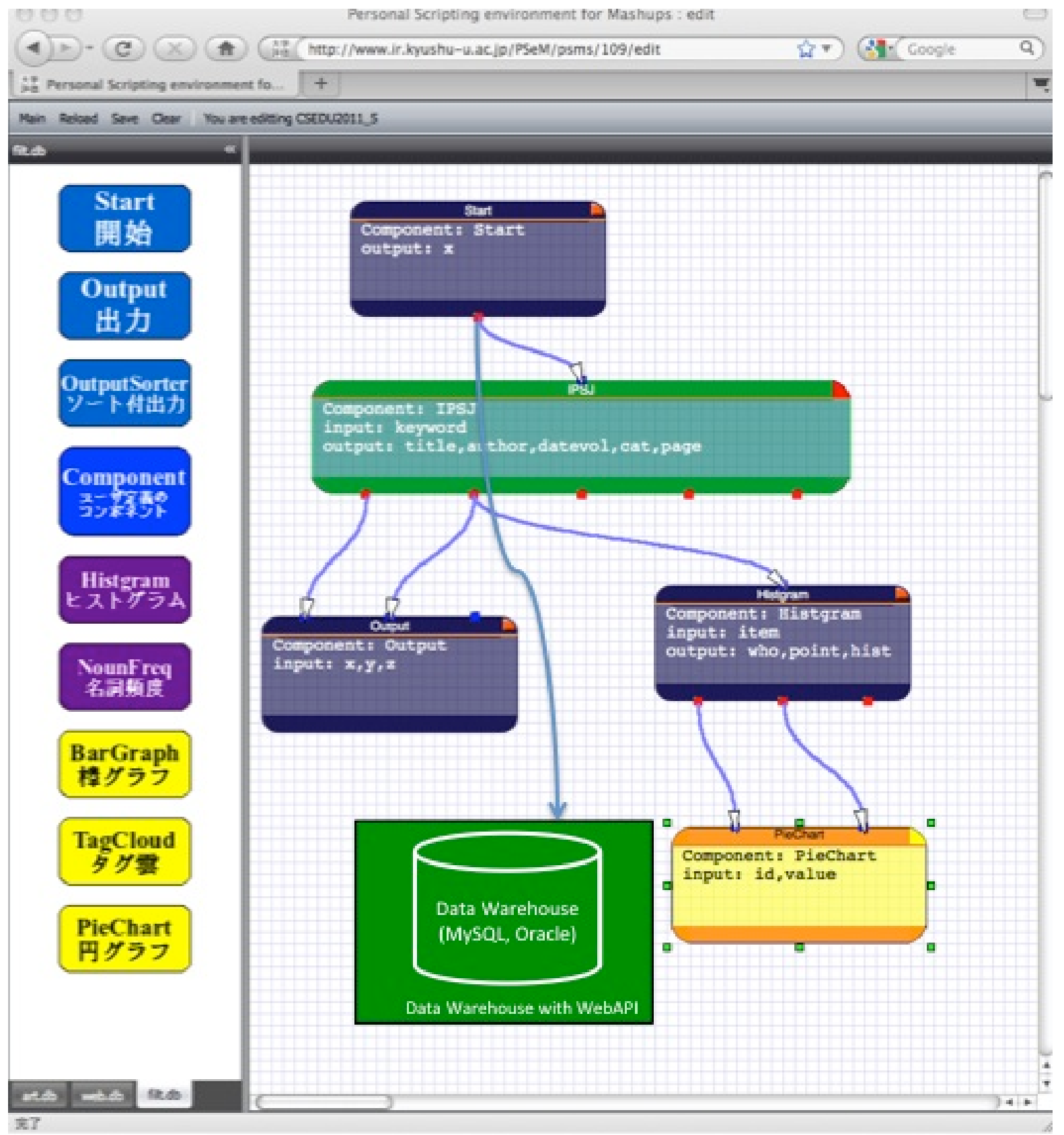

Figure 6: Overview of the proposing system 